\title{
AC 2010-773: POSTER: BRINGING ENGINEERING IDEAS INTO THE MATHEMATICS CLASSROOM - USING LINEAR PROGRAMMING TO INTEGRATE INDUSTRIAL ENGINEERING INTO THE HIGH SCHOOL CLASSROOM
}

Virginia Mayfield, Monterey High School

Kenneth Currie, Tennessee Technological University 


\title{
Bringing Engineering Ideas into the Mathematics Classroom: Using Linear Programming to Integrate Industrial Engineering into the High School Classroom
}

\begin{abstract}
:
As a participant in the TTU Research Experience for Teachers (RET) project, I conducted research alongside industrial engineers at Tennessee Tech University focused on the use of Interactive Activation and Competition (IAC), Bond Energy Algorithms (BEA) and Genetic Algorithms (GA) to work with the process of cellular manufacturing. Research outcomes showed preliminary success in the integration of these processes. The IAC was used to determine levels of similarity between certain parts being manufactured in a valve plant. The BEA was used to identify and display the groups existing in the resultant complex data set produced by the IAC. Finally, a GA was written to evaluate a final cost for the new manufacturing setup and then guide the parameters within the IAC to produce a better solution. The algorithm is ultimately looking for the solution that provides the lowest cost to the company. However, due to time constraints we oversimplified pieces of the process and now that these are known to work, the simplifications need to be removed from the process to reevaluate effectiveness. Most importantly, a more accurate, effective, and efficient way of evaluating cost is needed. A component of the RET experience was the development of a Legacy Cycle inquiry lesson unit intended to connect engineering research to high school mathematics and science curriculum standards. This poster session will focus on a mathematics legacy cycle I implemented with 32 students in the 2009-10 school year. The legacy cycle featured an exploration of linear programming, the simplex method, and very basic genetic algorithms to demonstrate to the student the various roles optimization can play throughout the engineering work force. Students presented solutions to a complicated three variable scenario to assess the knowledge they gained throughout this process. Students' learning and reactions to the cycle will be shared along with samples of their work. The Legacy Cycle proved effective as a means for translating industrial engineering concepts and research into my high school mathematics classroom.
\end{abstract}

